\title{
LA METÁFORA COMO MECANISMO DE INTELIGENCIA, CREACIÓN Y COMUNICACIÓN EN CIENCIAS DURAS E INGENIERÍA Y SU RECUPERO EN LA DOCENCIA UNIVERSITARIA
}

\author{
THE METAPHOR AS A MECHANISM OF INTELLIGENCE, CREATION AND \\ COMMUNICATION IN HARD SCIENCES AND ENGINEERING AND ITS RECOVERY IN \\ UNIVERSITY TEACHING
}

Humberto Manuel Magnasco ${ }^{1}$

Fecha de recepción: 23-07-2020

Fecha de aceptación y versión final: 07-07-2021

\section{Resumen}

Presentamos una síntesis de nuestra investigación sobre la validez epistémica del recurso a la metáfora en educación superior como mecanismo de inteligencia, creación y comunicación en "ciencias duras" e ingeniería. La misma fraguó en una tesis de maestría en docencia universitariai en la que rastreamos la presencia del mecanismo metafórico en las producciones inaugurales y basales de la ciencia moderna (Galileo, Newton, Faraday, Maxwell, Fourier, Ohm). El método empleado fue cualitativo y de alcance exploratorio, descriptivo y genético, infiriendo desde indicadores empíricos el potencial de inteligencia, creación y comunicación del mecanismo. El diseño fue dialéctico, proponiendo matrices de datos que dieron coherencia y entidad epistémica a los mismos. Detectamos en el avance del conocimiento científico en esta etapa fundamental el uso sine qua non de creativas metáforas, que haciendo pie en los ámbitos "extranjeros" de la vida diaria y de disciplinas ajenas, permitieron inteligir creativamente fenómenos intrigantes y desafiantes. Constatamos que estos últimos, produciendo en el espíritu una especie de "vacío hermenéutico", desafiaron al investigador y motorizaron un "llenado" creativo inicialmente metafórico (intentando conocer lo desconocido desde lo conocido). Dicha metáfora inicial — cognoscitivamente vívida e implicante- quedó luego disecada bajo un insípido ropaje matemático que la trocó en modelo. Concluimos que, si en la producción del conocimiento científico la metáfora ayudó creativamente a inteligir y matematizar los fenómenos, es oportuna su recuperación por parte de la docencia en orden a promover la construcción de los conocimientos científicos de una manera interesante y significativa.

Palabras clave: enseñanza de la ciencia- epistemología- metáfora - proceso cognitivo.

\section{Abstract}

We present here a synthesis of our research on the epistemic validity of the use of metaphor in higher education as a mechanism of intelligence, creation and communication in "hard sciences" and engineering. It was forged in a master's thesis in university teaching in which we trace the presence of the metaphorical mechanism in the inaugural and basal productions of modern science (Galileo, Newton, Faraday, Maxwell, Fourier, Ohm). The method used was qualitative and exploratory, descriptive and genetic in scope, inferring from empirical indicators the potential of intelligence, creation and communication of the mechanism. The design was dialectical, proposing data matrices that gave coherence and epistemic entity to them. We detect in the advance of scientific knowledge in this fundamental stage the sine qua non use of

${ }^{1}$ Bachiller en Filosofía y Teología, Ingeniero Electricista (UNR), Magister en Docencia Universitaria (UTN). Facultad Regional San Nicolás, Universidad Tecnológica Nacional. San Nicolás, Pcia. de Buenos Aires (Argentina). Correo electrónico: hmagnasco@ frsn.utn.edu.ar ORCID: 0000-0001-5672-1585. 
RIIE (2021), Año 12 (15), 68-92.

DOI: http://dx.doi.org/10.30972/riie.12155570
La metáfora como mecanismo de inteligencia, creación y comunicación en ciencias duras e ingeniería y su recupero en la docencia universitaria.

creative metaphors, which, by stepping into the "foreign fields" of daily life and from foreign disciplines, allowed creatively understand intriguing and challenging phenomena. We found that the latter, producing a kind of "hermeneutical vacuum" in the spirit, challenged the researcher and drove an initially metaphorical creative "filling" (trying to know the unknown from the known). This initial metaphor - cognitively vivid and implicating - was later made parched under a mathematical dress that turned it into a model. We conclude that if the metaphor creatively helped to understand and mathematize phenomena in the production of scientific knowledge, its recovery by teaching is timely in order to promote the construction of scientific knowledge in an interesting and meaningful way.

Key words: science teaching- epistemology- metaphor- cognitive process. 
RIIE (2021), Año 12 (15), 68-92.

DOI: http://dx.doi.org/10.30972/riie.12155570
La metáfora como mecanismo de inteligencia, creación y comunicación en ciencias duras $e$ ingeniería y su recupero en la docencia universitaria.

\section{Génesis del problema de estudio e hipótesis sustantiva}

Resumimos este primer punto en los siguientes incisos:

1.1) Una experiencia interesante como estudiantes: el motor de esta investigación ha sido la reelaboración —-desde la perspectiva docente- de una experiencia vivida como estudiantes de ingeniería: Un científico de renombre ii tenía la habilidad de llevarnos a la comprensión de fenómenos abstractos ${ }^{\mathrm{iii}}$ a través de imágenes y comparaciones traídas de la vida de todos los días. Ellas, lejos de alejarnos del riguroso saber sabio (Chevallard, 1985), eran un acicate para avanzar activa y significativamente en el meollo del fenómeno estudiado. Lograr inteligir desde el conocimiento familiar, nos ponía en el camino de la investigación -central en el nivel superior de educación-, pues nos inducía a hacernos preguntas surgidas desde la misma imagen metafórica, en un interesante diálogo entre el "dominio fuente" familiar y el "dominio meta" abstracto (Lakoff \& Johnson, 2007).

1.2) Una pregunta interesante y una "corazonada": ya como docentes, nos preguntamos en sentido epistemológico: ¿Por qué razón las imágenes procedentes de la vida diaria se muestran útiles y eficaces para inteligir y comunicar realidades abstractas en ámbitos científicos? Esta procedencia marca el traslado metafórico producido sobre esas imágenes desde lo familiar o conocido (dominio fuente) hacia lo que se intenta inteligir (dominio meta). Al mismo tiempo, nos hacíamos conscientes de que tal mecanismo opera con frecuencia en la vida cotidiana: cuando algo se presenta como difícil de asir conceptualmente o de expresar, es un recurso común buscar entenderlo, a través de lo conocido o familiar. Tal operación queda reflejada en el lenguaje coloquial: "(esto) es similar a (aquello)" o "(esto) es una especie de (esto otro)", es decir, aparece una visión que conecta dos ámbitos distintos mediante el traslado de una imagen familiar hacia el ámbito que se pretende inteligir. En este traslado (en griego: metafero), opera una tensión que permite ver dos cosas en una: una desconocida desde otra conocida. De este modo, lo problemático comienza a inteligirse, no sin cierta incomodidad, pero prometedora y significativamente. La concepción de la metáfora como "visión de dos en uno" fue desarrollada por Max Black: cuando usamos una metáfora (en griego "traslación") tenemos en una sola expresión dos pensamientos de cosas distintas interactuando simultáneamente (Black, 1966). Según Aristóteles usar bien la metáfora equivale a ver con la mente las semejanzas (Aristóteles, 2004). Ver las semejanzas (en griego: "analogías") entre dos cosas, es la actuación del ver metafórico que se realiza en la interacción o tensión viva entre dos ámbitos diversos que resultan en una fructífera conexión, ya que en ella se infiere en forma abductiva un significado (Peirce, 2003; Samaja, 2004). Desde la perspectiva educativa la relación que este mecanismo establece con un alumno activo y protagonista en la construcción de sus saberes resultaba atractiva, máxime en el ámbito de la educación superior.

La pregunta interesante que formulamos concomitaba con el surgimiento de una "corazonada científica" (ASA, 1949), es decir, con el sentimiento de una posible respuesta como hipótesis a investigariv, un sentir intuitivo de que la cosa podría ser de ese modo. En ese "podría" estamos introduciendo una inferencia abductiva basada en toda una experiencia de vida, heredada y personal, científica y cotidiana, que podríamos resumir en nuestra praxis existencial. ¿Qué ingredientes de nuestra praxis se sumaban en el sustento de la corazonada? Sobre todo, los estudios lingüísticos: ellos nos habían llevado a una obra que demostraba como el mecanismo metafórico estaba presente en la constitución y en la dimensión semántica del lenguaje natural (Lakoff \& Johnson, 2007). La visión de "dos en uno" que entraña el ver metafórico 
RIIE (2021), Año 12 (15), 68-92.

DOI: http://dx.doi.org/10.30972/riie.12155570
La metáfora como mecanismo de inteligencia, creación y comunicación en ciencias duras $e$ ingeniería y su recupero en la docencia universitaria.

permitió - en este caso- generar un vocablo para nombrar lo que aún no había sido nombrado y cubrir un "vacío semántico" (las "patas" de la mesa o las "alas" del avión son ejemplos del resultado de este mecanismo de cubrimiento). Tal operación de nombrar lo aún innombrado desde lo conocido ha quedado reflejada en las etimologías de los vocablos. En esta línea, José Ortega y Gasset entendía que la creativa metáfora era un "suplemento a nuestro brazo intelectivo" (Ortega y Gasset, 1985, p. 604) que llegaba a asir -inteligiendo y revistiendo con palabras- aquello que se presentaba prima facie como indómito o inasible.

Así, como el proceso metafórico funcionaba cognitivamente en la vida diaria y en la constitución del lenguaje natural, dando significatividad y expresión a sus producciones, nuestra corazonada era esta: ¿Estará funcionando también la metáfora como recurso cognitivo en la base de los modelos lógico-matemáticos productos del avance científico? Por lo que nos preguntamos, ya en orden a responder con una investigación: ¿Cómo surgen los modelos que hacen avanzar la ciencia? Siendo nuestra respuesta conjetural o inferencia abductiva de hipótesis (Peirce, 2003; Samaja, 2004): Los modelos que hacen avanzar la ciencia dura surgen mediante o se basan en procesos metafóricos sustentados en conocimientos que provienen de la vida cotidiana y familiar. Esta fue nuestra hipótesis sustantiva de investigación.

Nos resultaba relevante la investigación empírica en las obras fundantes de la ciencia moderna ya que, de confirmarse la corazonada expresada, se abrían interesantes perspectivas para la docencia —que en el ámbito de las ciencias duras y la ingeniería recoge las producciones de tales obras basales-, pues si en la producción del conocimiento científico opera la metáfora como mecanismo motorizante del inteligir, ¿por qué no recuperarla en la actividad docente? $Y$ un abanico de interrogantes relacionados se insinuaban: el proponer la metáfora en un aula de educación superior ¿es una propedéutica válida epistemológicamente hablando?

Como docentes de enseñanza superior ¿nos es válido acudir a este recurso o es traicionar lo esperable de la docencia en el nivel? Si el núcleo de los modelos de tipo lógico-matemático es metafórico ¿cómo se pasa de la metáfora al modelo matemático? Así, el problema general que abordamos y al que responde la hipótesis recién lanzada, es la incidencia de la metáfora en la construcción del conocimiento científico en las llamadas "ciencias duras", su pertinencia epistemológica y la oportunidad que esto abre a la docencia en el nivel superior (en dónde, por un lado se intenta promover un alumno activo —en la estela del investigador y el científico- y , por otro, se le ofrece para digerir un conocimiento en la forma de un monumento axiomático-deductivo, bien trabado y sin fisuras, frente al cual no cabe más que la contemplación).

\section{Objetivos}

Como objetivos nos propusimos en sintonía: 1) manifestar la pertinencia de la metáfora en el cubrimiento del "vacío hermenéutico", es decir, como mecanismo de inteligencia, creación y comunicación frente a fenómenos a primera vista desconcertantes; 2) manifestar la lógica que opera en el llamado contexto de descubrimiento (es decir, cómo se llenan los "vacíos hermenéuticos" a través de la lógica de la inferencia abductiva, la cual entraña el mecanismo metafórico); 3) probar la pertinencia empírica de la metáfora como descriptiva de lo real; y 4) demostrar que el revestimiento matemático de la metáfora es posible. 
RIIE (2021), Año 12 (15), 68-92.

DOI: http://dx.doi.org/10.30972/riie.12155570
La metáfora como mecanismo de inteligencia, creación y comunicación en ciencias duras $e$ ingeniería y su recupero en la docencia universitaria.

\section{Objeto de estudio y metodología en base a matrices de datos}

El objeto modelo de nuestra investigación fue "la metáfora como mecanismo de inteligencia, creación y comunicación en ciencias duras e ingeniería", objeto que resulta interesante para la docencia por lo que hemos comentado. Como observamos, este objeto es un objeto construido, pues en base nuestros intereses hemos integrado como aspectos sobresalientes a tener en cuenta sus dimensiones cognitivas, creativas y pragmáticas. A estas dimensiones asociadas al mecanismo debemos hurgarlas en la empiria, concretamente en las obras fundamentales de la ciencia moderna, y para esto debemos definir indicadores que las señalen.

Metodológicamente, aparece dando sustento epistémico a tal objeto modelo una estructura matricial (Samaja, 2004), dentro del marco de la perspectiva "operacional" (Ladrière, 1978) que se define por su carácter "dialéctico" o "transaccional"v, es decir, la operación puesta en juego en la investigación es constructiva (no meramente descriptiva) del objeto de estudio. Reconocemos en este objeto de estudio, en terminología de las matrices de dato, nuestra unidad de análisis (UA), esto es, el recurso a la metáfora en las fuentes analizadas (ver infra punto 4).

Pero, como nos interesa no sólo detectar el uso de la metáfora sino también los aspectos entrañados que la constituyen como mecanismo de inteligencia, creación y comunicación, tal UA ha sido indagada en cuanto a su lógica o fundamento epistemológico, es decir, la lógica que permitió al científico inteligir los fenómenos. Si hay una lógica, podemos describir los mencionados procesos metafóricos como inferenciales, es decir, no se trata de un mero modo de hablar tendiente a la comunicación, sino que inferencias en el dominio fuente se trasladan a inferencias en el dominio meta (Gentner \& Gentner, 1982). Esta perspectiva indagatoria define, en el lenguaje de las matrices de datos, la variable (V) a "valorar" en la UA. Así podemos resumir diciendo que el proceso metafórico que es la UA es valorado en su lógica o dimensión epistemológica, lo cual define la variable. Esta variable, a su vez, tiene dimensiones (D) interesantes para nosotros e interpenetradas entre sí: a) la cognición conseguida o la construcción de conocimiento producida que permite desentrañar la lógica de esos fenómenos intrigantes y es semilla de un desarrollo posterior, b) la dimensión creativa en cuanto que estableciendo relaciones fecundas entre ámbitos "extranjeros" se construye operativamente el objeto en estudio y c) la comunicación lograda desde la visibilidad imaginativa aportada (estos tres aspectos o dimensiones constituyen la lógica involucrada en el mecanismo). Claramente, así especificado, este objeto de estudio no es directamente visible en la empiria, es decir: si bien detectamos positivamente la operación del mecanismo metafórico (UA), esto sólo no alcanza, debemos definir indicadores (I) (Samaja, 2004) que nos permitan inferir las dimensiones (D) de la variable (V). Hemos propuesto los siguientes:

- Indicador 1: la metáfora cubre o llena efectivamente el vacío hermenéutico y permite inferir propiedades desde lo conocido, que de otro modo hubiesen permanecido ocultas (dimensión cognoscitiva) y que habilitan y son acicate de un desarrollo posterior (Conant, 1963). El procedimiento empírico (P) que se asocia a este indicador es constatar la desaparición estable de tal vacío, es decir, el éxito de tal cubrimiento mediante la metáfora manifestado en que su dominio meta se convierte en dominio fuente de nuevas producciones científicas.

- Indicador 2: la metáfora establece una conexión fructífera, mutuamente constructiva, entre ámbitos prima facie ajenos entre sí (dimensión creativaconstructiva). El procedimiento empírico que se asocia a este indicador es constatar la 
RIIE (2021), Año 12 (15), 68-92.

DOI: http://dx.doi.org/10.30972/riie.12155570
La metáfora como mecanismo de inteligencia, creación y comunicación en ciencias duras $e$ ingeniería y su recupero en la docencia universitaria.

producción de un efecto heurístico constructor de conocimiento por el traslado metafórico, esto es, se detecta una conexión "funcional" de ámbitos diversos unidos por el mecanismo semiósico-metafórico que permite inferir funcionamientos en el dominio meta a partir de funcionamientos análogos en el ámbito ya conocido o familiar.

- Indicador 3: hay eficacia pragmática al hablar de lo abstracto a través de lo familiar, es decir, la metáfora se constituye en un medio pedagógico que invita a inteligir en un ámbito de comunicación. El procedimiento empírico que se asocia a este indicador es constatar que se produce la "naturalización" de tal cubrimiento. Dicho de otro modo, con el paso del tiempo resulta una catacresis de los términos producidos y sus vinculaciones funcionales, esto es, se produce el olvido del origen metafórico de su producción (por ejemplo, la "corriente", los "conductores", las "fuentes" que desde un origen situado en el dominio de los flujos de agua se transforman en vocabulario técnico del dominio eléctrico).

Como se observa, entre la empiria "bruta" y nuestra unidad de análisis con sus variables, dimensiones, indicadores y procedimientos asociados, median esquemas provenientes del sujeto que interroga e investiga y que hacen concluir a Samaja: "Todo dato está cargado de praxis" (2004, p. 194); a esto nos referíamos como la perspectiva operatoria o transaccional puesta en juego en nuestra metodología. vi Hemos rastreado los indicadores de las dimensiones de la variable de la unidad de análisis en las obras claves de los investigadores analizados (ver infra, punto 4.1) por lo que nuestra indagación resulta propiamente empírica al hurgar los "rastros" metafóricos en los mismos papers y obras de los científicos que sentaron las bases de la ciencia moderna, sin contentarnos con posibles y oportunos testimonios de terceros.

Recapitulando: el tipo de método y el consiguiente diseño que sustentó la investigación es dialéctico y se materializa en un sistema de matrices de datos, en varios niveles de integración: niveles supra-unitarios $(\mathrm{N}+1, \mathrm{~N}+2, \mathrm{~N}+3)$ de los marcos teóricos), nivel unitario o de anclaje $(\mathrm{N})$ (donde propiamente se encuentra la unidad de análisis con sus variables y dimensiones) y un nivel sub-unitario ( $\mathrm{N}-1)$ en el que el sistema toma contacto con la empiria a través de los indicadores y procedimientos declarados. Se incluyen dos matrices coordinadas del ámbito lingüístico (Lakoff \& Johnson, 2007) que abonan una coherencia con el conocimiento bien establecido (Samaja, 2004). Ofrecemos en el Apéndice este sistema de matrices de datos construido para observar cómo se enlaza la construcción teórica con la base empírica.

En cuanto a la naturaleza de los datos ellos son cualitativos, en tanto que no se están considerando aspectos medibles o cuantificables. En cuanto a los alcances de los resultados de la investigación, la misma es de tipo: a) exploratorio en tanto que trata de indagar la presencia del mecanismo metafórico en ciencia desde el punto de vista epistemológico y con vinculaciones poco estudiadas con otros campos (como la lingüística y la relación pensamiento-realidad), b) descriptivo y genético en tanto se generan hipótesis sustantivas acerca de las formas de ser y de los mecanismos de génesis de los objetos de estudio (Samaja, 2004).

\section{4. $\quad$ Fuentes y muestra}

Es necesario justificar lo recién manifestado sobre el alcance descriptivo y genético de la investigación, en otras palabras, el alcance de nuestra hipótesis sustantiva y su relación dialéctica con las fuentes y la muestra. Han sido de gran valor como fuentes de esta investigación las obras fundantes originales de Newton, 
RIIE (2021), Año 12 (15), 68-92.

DOI: http://dx.doi.org/10.30972/riie.12155570
La metáfora como mecanismo de inteligencia, creación y comunicación en ciencias duras $e$ ingeniería y su recupero en la docencia universitaria.

Faraday, Maxwell, Fourier y Ohm que establecen las bases de la mecánica y el electromagnetismo clásicos y que son elementales en los currículos de ingeniería y de las ciencias duras. El modo de proceder que va construyendo modelos desde la operación metafórica -y cuya síntesis más lograda está dada en la mecánica newtoniana y en las 4 ecuaciones de Maxwell-, constituyó una base firme para toda la física. Maxwell explicita su camino: "In order to obtain physical ideas without adopting a physical theory we must make ourselves familiar with the existence of physical analogies"vii (Maxwell, 1855, p. 2). Einstein reconoce que "estaba justificado creer que por el camino iniciado con tanto éxito por Faraday y Maxwell se iría encontrando poco a poco una base firme para toda la física" (Einstein, 1983, p. 39) (el subrayado es propio) y, según Herrero, este camino ha servido "de fundamento metodológico a otras teorías físicas" (2012, p. 81). Por esto, aunque el análisis de los registros del procedimiento que logra tal potencia explicativa se refiere a casos concretos (ver punto 7), las conclusiones que se desprenden no se circunscriben a estos casos, sino que pueden ser extendidas más allá de ellos como algo que naturalmente comienza a replicarse desde el éxito obtenido. Así lo resumen Faraday y Bolzman:

I believe that, in the pursuit of physical science, the imagination should be taught to present the subject investigated in all possible, and even in impossible views; to search for analogies of likeness and (if I may say so) of opposition inverse or contrasted analogies [...] We could not reason about electricity without thinking of it as a fluid, or a vibration, or some other existent state or form viii (Faraday, 1859, pp. 481-482)

No podemos reprochar a una mera analogía que cojee en algunos aspectos. Por ella se interpretaron [...] la teoría elástica de la luz, la teoría de los gases, [...] etc., nada más que como analogías mecánicas, y finalmente la filosofía generalizó las ideas de Maxwell hasta fundar una doctrina según la cual el conocimiento mismo no es otra cosa que el hallazgo de analogías. Con esto los métodos científicos fueron definidos de nuevo y la Ciencia habló nada más que mediante comparaciones. (Boltzmann, 1986, p. 54) (el subrayado es propio)

La metáfora o traslado metafórico que opera en estas situaciones ayuda a "trepar la cuesta abstracta" (Bruner, 2004, p. 58), transformándose de metáfora a modelo cuando un ropaje lógico matemático sugerido desde el dominio fuente la reviste. Esta operación ha sido referida por Maxwell: "By a physical analogy I mean that partial similarity between the laws of one science and those of another which makes each of them illustrate the other"ix $(1855$, p. 2). Samaja refiere que J. Piaget dice que un modelo resulta de "la proyección de un esquema lógico matemático en la realidad" (2004, p. 32). Tomando este concepto de modelo, podemos decir que la metáfora es anterior a ese modelo y es base del mismo. Ese ropaje lógico matemático, que también es incoado desde el traslado metafórico, la trueca en modelo.

4.1) En base a lo dicho, hemos hurgado los indicadores de las dimensiones del proceso metafórico fundamentalmente en las obras basales de la mecánica y electromagnetismo clásicos. Entre éstas, destacamos: Bacon (1949); Galilei (1981), Fourier (1822), Newton (1846) ${ }^{x}$, Newton (1871), Newton (1982), Newton (2006), Newton (2011), Priestley (1967), Thomson (1872), Faraday (1855), Faraday (1859), Maxwell (1855), Ohm (1827). Sumamos en este grupo, en tanto investigaciones 
RIIE (2021), Año 12 (15), 68-92.

DOI: http://dx.doi.org/10.30972/riie.12155570
La metáfora como mecanismo de inteligencia, creación y comunicación en ciencias duras $e$ ingeniería y su recupero en la docencia universitaria.

empíricas contemporáneas en este campo, a Gentner y Gentner (1982) y Boltzmann (1986). Anexamos secundariamente obras matemáticas y físicas de los siguientes tenores:

4.2) obras que incluyen datos históricos referidos al contexto científico, por ejemplo: Weinberg (2016), Boido (1998), Moledo (2013), Rey Pastor y Babini (1985). Estas obras suelen recuperar implícitamente las metáforas operantes en el contexto de descubrimiento;

4.3) las expresiones lingüísticas y estructurales de sus producciones en libros de texto para estudiantes de ciencia e ingeniería, por ejemplo: Halliday \& Resnick (1977). Estas obras nos mostraron como la reorganización axiomático-deductiva arrojaba "por la ladera" — una vez subida "la cuesta abstracta" (Bruner, 2004, p. 58)— a la metáfora presente en 4.1 y 4.2 ;

4.4) textos divulgativos de la ciencia - sin fórmulas matemáticas- que recuperan, sabiéndolo o no, las metáforas originales bajo pretexto de didáctica y desde consideraciones epistemológicas. Por ejemplo: Hewitt (2007), Vallejo (2005), Moledo (2013), Einstein \& Infeld (1974), Penrose (1996);

En base a los indicadores empíricos propuestos, la muestra es intencional y se fue saturando a medida que avanzó el análisis de los resultados.

\section{Estado de la cuestión y originalidad del estudio}

Hemos encontrado estudios que constatan la importancia del uso de analogías en ciencia, pero sin detenerse - porque sus intereses son otros- en el papel que juega la metáfora en la lógica del establecimiento de analogías y la construcción de modelos matemáticos. En el marco teórico y su prolongación los iremos mencionando (ver infra punto 6). Respecto de lo propiamente hermenéutico, señalamos la importancia de los estudios sobre la metáfora de Ricœur (1977), que se encuentran en la estela de Heidegger y Gadamer. En cuanto a lo propiamente epistemológico, Palma (2004) propone una visión que coloca a la metáfora en ciencia como ingrediente de selección en un marco epistémico genético-evolutivo.

Reconociendo la gran importancia de estos antecedentes, nuestro trabajo se ha conducido con otros intereses y, por tanto, por otro camino: por el de la subjetividad concreta del científico que — situada histórica-geográfica y culturalmente- recurre a una metáfora para interpretar un hecho desconcertante. El recurso a lo conocido en otro ámbito, más familiar pero ajeno al tema, es una maniobra osada de la imaginación y la creación. Darle su fundamento epistemológico, en orden a avalar su recuperación docente en la educación superior, ha sido lo original de nuestra investigación. En el punto 7 analizaremos concretamente las metáforas más importantes utilizadas por los mismos científicos como recurso de cubrimiento del vacío hermenéutico, su lógica, su incipiente revestimiento matemático y la posibilidad de su recuperación en la docencia como pertinente trasposición didáctica.

\section{Marco conceptual y su reelaboración en la investigación}

Resumimos este punto en los siguientes incisos:

6.1) El núcleo metafórico de los modelos y la recuperación de "lo conceptual" en la docencia: para varios científicos y epistemólogos —como M. Black (1966), E. Nagel (2006), Rom Harré, Mary Hesse (1970) — las metáforas en ciencia no son ayudas iniciales a descartar lo antes posible, sino el núcleo de la teoría que la seguirá 
RIIE (2021), Año 12 (15), 68-92.

DOI: http://dx.doi.org/10.30972/riie.12155570
La metáfora como mecanismo de inteligencia, creación y comunicación en ciencias duras $e$ ingeniería y su recupero en la docencia universitaria.

haciendo fecunda (Black, 1966). En palabras de este autor "quizás toda ciencia tenga que empezar con metáforas y acabar con álgebra; y es posible que sin la metáfora nunca hubiese existido álgebra alguna" (p. 237). En otras palabras, esto último es lo que hemos sostenido conjeturalmente y probado en la investigación: el modelo lógico matemático hace pie en la metáfora, la cual asume una dimensión cognoscitiva epistemológica $^{\mathrm{xi}}$. Lo referido por Max Black nos invita como docentes, a no olvidar este núcleo del modelo, porque si el producto ofrecido a los alumnos no es más que álgebra, la pérdida de lo conceptual del fenómeno descrito ya es un hecho.

6.2) La propuesta docente de conocer creativamente y no mero re-conocer: este traslado desde lo conocido hacia lo que se intenta conocer, no consiste en embretar o forzar una interpretación (donde todo resulta ser copia de lo que ya se conocía) sino que estriba en un proceso de uberty, vocablo usado por Ch. S. Peirce para referirse a la capacidad heurística o fructífera de la inferencia que él llama abducción (Peirce, 2003). Con ayuda de las categorías de la semiosis peirceana y de las categorías lógicas hegelianas (Hegel, 1982), hemos ubicado al mecanismo metafórico en el seno mismo del proceso de inferencia abductiva como instancia que permite obtener la regla para que funcione la abducción (ver punto 6.3).

6.3) Una lógica creativa a recuperar por la docencia: lo que hemos referido en el punto 1.2) como un ver dos cosas en una, se relaciona con una lógica dialéctica de tercio incluso -que aparece en ciencia ante las paradojas de los fenómenos cuánticos (Lupasco, 1963) - , es decir, implica una violación de la lógica tradicional.

No violar un orden lógico consiste en manejarse principalmente con razonamientos deductivos cuya fortaleza lógica tiene un precio: su infecundidad cognoscitiva (la conclusión está incluida en la premisa mayor o regla). Teniendo esto en mente, Peirce entendió los distintos tipos de razonamientos como "desórdenes" de la deducción. Observó que hay dos modos, cognoscitivamente útiles, de desordenar el razonamiento deductivo expresado en la secuencia tradicional "1. Regla - 2. Caso - 3. Resultado", uno de ellos arroja la inducción: Caso - Resultado - Regla, el otro la abducción: Resultado - Regla - Caso. El grado de uberty aumenta con este desorden a la vez que disminuye su fortaleza lógica (Rodríguez Rodríguez, 2005). La abducción o "retroducción" es un tipo de inferencia que ante fenómenos que "piden" explicación o generan un vacío hermenéutico, atisba un esquema conocido que permite inteligirlos ${ }^{\text {xii. }}$.

Este esquema trasladado genera justamente una hipótesis:

La [...] abducción proporciona al razonador la teoría problemática que la inducción verifica. Al encontrase a sí mismo enfrentado con un fenómeno distinto a lo que hubiera esperado bajo esas circunstancias [Resultado], examina sus características y advierte algún carácter o relación entre ellas singular [traslado metafórico], que al instante reconoce como característico de alguna concepción que ya está guardada en su mente [analogía = Regla], de modo que es sugerida una teoría que explicaría [...] eso que es sorprendente en el fenómeno [abducción del Caso a partir de la Regla]. (Peirce, 2001, p. 2776) (los corchetes son propios).

Así, es el proceso metafórico el que permite obtener la regla para que funcione la abducción.

6.4) Describir algo con verosimilitud para quien aprende: dos de los principales teóricos de la llamada perspectiva cognitivista de la metáfora son George 
RIIE (2021), Año 12 (15), 68-92.

DOI: http://dx.doi.org/10.30972/riie.12155570
La metáfora como mecanismo de inteligencia, creación y comunicación en ciencias duras $e$ ingeniería y su recupero en la docencia universitaria.

Lakoff y Mark Johnson, para quienes "la esencia de la metáfora es entender y experimentar un tipo de cosa en términos de otra" (2007, p. 41). En este experimentar una cosa en base a otra conocida, se entraña el aprendizaje significativo. Dicen los autores que la idea sobre el significado dominante en la filosofía occidental y la lingüística "tiene muy poco que ver con lo que la gente encuentra "significativo" en su vida" (p. 33).

Ellos analizaron las metáforas y conceptos presentes en el lenguaje cotidiano, y concluyeron que nuestro sistema conceptual es metafórico y justamente lo es debido a la significatividad que en el inteligir se produce al conocer lo desconocido por lo conocido (se produce un sentimiento de verosimilitud, que -como adelantamos en 1.2- es una "corazonada"). Para que sea posible tal sistema y el conocimiento que de él se deriva es necesario poder conocer algo directamente, es decir, sin metáforas (para evitar una regresión ad infinitum del mecanismo): son los conceptos de base física corporal, tales como "arriba-abajo" y "dentro-fuera" (p.50) y donde se encuentran las bases del edificio de nuestra comprensión.

6.5) Valor cognoscitivo de la metáfora y aprendizaje significativo: reforzando la idea de verdad como algo que se experimenta personalmente -o en una experiencia de protagonismo (Samaja, 1996; 2004)—, podemos mencionar antecedentes interesantes. Preludian esta visión Nicolás de Cusa y Giambattista Vico.

Para el cusano, el hombre siempre que aprende algo lo hace mediante algún tipo de proporción ("proporción" es uno de los significados del griego analogía) entre lo que ya conoce y lo que quiere conocer (Nicolás de Cusa, 1973). En torno al aspecto pedagógico es importante su concepto del hombre como microcosmos: en sí mismo y en su historia el hombre encontrará las herramientas de la proporción o de la analogía.

Por su parte, Vico sienta su famoso principio: lo verdadero es lo obrado (verum ipsum factum) (Vico, 1995), con lo cual reformula el concepto de hombre como microcosmos: más que "espejo del mundo natural" el hombre es un reflejo de lo obrado por él mismo, y de algún modo en los objetos inteligidos quedan incorporados "ingredientes" humanos (los objetos son construidos dialécticamente, hay una transacción).

6.6) Valor cognoscitivo de la metáfora y construcción de los conocimientos: la línea pedagógica acorde al constructivismo, en la que se inserta nuestro estudio, engarza ideas de J. Dewey (conocimiento como "transacción"), de E. Claparède (paralelos entre el investigador y el niño que juega), de J. Piaget (invariantes funcionales en la evolución del conocimiento) y de S. Papert (importancia de los objetos tecnológicos transaccionales en la dinámica del aprendizaje). Su común denominador es que los conceptos para ser asimilados deben encarnarse, es decir, deben de algún modo hacerse visibles o ser sentidos desde lo ya conocido, para así poder anidar en la inteligencia o ser inteligidos. De este modo, resultarán verdaderamente conceptos, esto es, concebidos endógenamente, construidos con materiales interiores en la mente del aprendiz. En educación este proceso invita a huir de un operativismo abstracto (ejercitaciones), que concomita con la carencia de significado, la atomización y que no contribuye a un aprendizaje significativo.

Entendemos que la metáfora es el proceso que motoriza la significatividad al traer la imagen desde el ámbito familiar y permitir esa encarnación sensible del concepto.

6.7) Los vacíos hermenéuticos: en cuanto a los vacíos generados en el contexto de descubrimiento, y que justamente son la ocasión de un llenado por vía metafórica, hemos investigado documentalmente el tema para luego señalar los 
RIIE (2021), Año 12 (15), 68-92.

DOI: http://dx.doi.org/10.30972/riie.12155570
La metáfora como mecanismo de inteligencia, creación y comunicación en ciencias duras $e$ ingeniería y su recupero en la docencia universitaria.

indicios de tales vacíos en la investigación empírica. Con la idea de vacío hermenéutico queremos referirnos a un "vacío interpretativo" que se produce frente a unos hechos que nos resultan desconocidos, intrigantes, como a primera vista "incoherentes". Aquí aparece un acicate intelectual — como la otra cara de la misma moneda- que impulsa un proceso activo de búsqueda de llenado de ese vacío en una especie de "horror vacul".

La idea original de "vacío hermenéutico" lo es en tanto se corresponde con la idea de "horror vacui" que es lo que especifica a ese vacío y puede favorecer la actividad del alumno. ¿Qué testimonios hemos encontrado sobre tales vacíos? Alfred Korzybski (1951) y Roger Penrose (1996) recuerdan que J. Hadamard en su obra Psicología de la creación en el campo de la Matemática aborda el estudio del tipo de pensamiento que utilizan matemáticos y físicos destacados a la hora de resolver problemas y proponer soluciones creativas. Hadamard registra que la mayoría de ellos admiten que utilizan un pensamiento de tipo visual, debiendo luego buscar con gran trabajo las palabras o los signos formales que lo traduzcan científicamente; citan testimonios de Einstein, Francis Galton, del propio Hadamard y del mismo Penrose).

Es decir, hay un desacople o intersticio entre la palabra que "dice y explica" y la realidad que pretende ser dicha y explicada, no hay - como buscó el primer Wittgenstein (el del Tratactus Logicus Philosophicus) y tiempo antes los proyectistas ingleses (Laborda Gil, 1981) — un lenguaje de tipo "pictórico", esto es, un lenguaje que "pinta" la realidad en "perfecto acople" porque está liberado de ambigüedades metafóricas y ficciones metafísicas.

El cubrimiento de este intersticio, en tanto vacío semántico, es metafórico y ha sido estudiado por Lakoff \& Johnson (2007). Con respecto al vacío hermenéutico en nuestra investigación empírica, mostramos que ese "intersticio" es cubierto por un salto metafórico que mapea el dominio meta en base a un esquema conocido o familiar (ver punto 7). Este desacople o intersticio aquí manifestado es otro nombre del vacío hermenéutico. El llenado metafórico del mismo es insinuado por Ernst Cassirer que define al hombre más que como animal racional como animal simbólico (Cassirer, 1968). En sintonía con Cassirer, Piaget habla de una función simbólica en el ser humano más amplia que el lenguaje —que es sólo una de sus manifestaciones-, así el pensamiento (que siempre es simbólico) precede al lenguaje o al discurso racional (Piaget, 1991). Estos testimonios proponen un pensamiento anterior al lenguaje (que "dice y explica"), al menos en una primera etapa. La misma es llamada por Korzybski "nivel silencioso" y es, según él, una ocasión de creatividad:

si en nuestra búsqueda general de una semejanza entre los dos niveles, el silencioso y el verbal, "pensamos" sin palabras, con imágenes, o con visualizaciones (que implican estructura, y por tanto, relaciones) podremos descubrir nuevos aspectos y relaciones en los niveles silenciosos [construcción del objeto] y podremos formular importantes resultados teóricos. Prácticamente todos los grandes avances se han logrado de esta manera. (Korzybski, 1951, p.3) (los corchetes son propios)

En una segunda etapa, ese pensamiento silencioso se revestirá de lenguaje —no sin dificultades- para producir una primera expresión comunicable. Entendemos que esta última es el resultado de procesos metafóricos que permiten obtener la regla para que funcione el razonamiento abductivo que termina cubriendo el vacío. Los vacíos marcan una falta "de acople" pero no se identifican con la "nada"; ellos están 
RIIE (2021), Año 12 (15), 68-92.

DOI: http://dx.doi.org/10.30972/riie.12155570
La metáfora como mecanismo de inteligencia, creación y comunicación en ciencias duras $e$ ingeniería y su recupero en la docencia universitaria.

como "preñados" y desde la cantera de analogías (Samaja, 2004) dan a luz una metáfora pertinente.

\section{Reporte de las metáforas operantes en las bases y desarrollo de la ciencia moderna y la oportunidad de su recuperación en docencia}

A continuación, reportamos las metáforas más importantes utilizadas por los mismos científicos desde los albores de la ciencia moderna. Elegimos las más representativas, intentando recuperar la progresión en el éxito de ese inteligir en el que se van conquistando nuevas parcelas del saber (mediante la satisfacción de los indicadores mencionados). Notará el lector que, sin solución de continuidad, se pasa de concepciones míticas, religiosas y metafísicas — presentes en los desarrollos 7.1 y 7.2- a concepciones más duras, matemáticas y mecánicas - 7.3 y siguientessiendo indudable que la raíz mítica, religiosa y metafísica sigue presente en el desarrollo posterior.

7.1) Metáfora de Galileo Galilei: La naturaleza (dominio meta) es un libro escrito en caracteres matemáticos (dominio fuente) (Galilei, 1981): esta metáfora de Galileo resume el espíritu de la ciencia moderna y constituye su gran marco de fe y actuación. Expresa la convicción de que la naturaleza está "matematizada" y es el motivo que lleva a revestir con el número y la proporción a las metáforas de base. Esta convicción es el último eslabón de una cadena de traslados metafóricos que resumimos a continuación. Veremos que dichos traslados conducen a dos posturas enfrentadas sobre la naturaleza de la matemática: la de Giordano Bruno y la de Galileo Galilei que es la que prevalece. La matemática desde antiguo fue un reducto esquemático o "alfabeto" constituido por "número, medida y orden [...] que permitía reducir la multiplicidad a unidad" (Rey Pastor y Babini, 1985, p. 1;13). Esta incipiente matemática terrena (dominio fuente) se traslada temprana y metafóricamente al cielo en donde comienzan a verse reflejados sus estables, regulares y esquemáticos rasgos (dominio meta), a la vez que tal conexión celeste le va asociando cierta dimensión divina.

Según Platón y Aristóteles las entidades de la bóveda celeste son inmateriales y semidivinas y sus movimientos se producen según figuras geométricas perfectas circulares y con movimiento uniforme, así se establece un dualismo entre el "mundo sublunar" y el "mundo supralunar" divinizado. El advertir, por parte de la razón filosófica que, si bien no existe en el mundo sublunar una circunferencia perfecta, el hecho de concebirla como idea indica que la misma debe existir como arquetipo de todas las circunferencias imperfectas. Tales razonamientos, conducen a la gnoseología platónica a establecer una relación o proporción entre el conocimiento de las realidades mundanas y la divinizada matemática que es su fundamento. Ella es parte esencial del "mundo de las ideas" que es una "hiper realidad" que da fundamento, proporción, orden y armonía al cosmos (Hirschberger, 1997). Tal mundo de las ideas es — según Platón en el Timeo — "forma y número" y el ejemplar que —en tanto fundamento- nunca es alcanzado plenamente por las realidades humanas y terrenas (que son sus copias degradadas). El aspecto lógico de los contenidos y conexiones lógicas de las ideas es su logos que adquiere - por lo dicho- cierta dimensión matemática. Pero contrariamente a lo que pensará luego Galileo, la "forma y número" que da fundamento al conocimiento de lo real no se reduce a "forma geométrica y número aritmético" ya que el binomio comprende también los ejemplares de la ética del obrar y la idea de justicia, cuyas copias jamás tienen en la vida terrena la perfección de su idea (Windelband, 1953) (como tampoco ninguna circunferencia terrena tiene la perfección de su idea). 
RIIE (2021), Año 12 (15), 68-92.

DOI: http://dx.doi.org/10.30972/riie.12155570
La metáfora como mecanismo de inteligencia, creación y comunicación en ciencias duras $e$ ingeniería y su recupero en la docencia universitaria.

El obispo y teólogo cristiano conocido como San Agustín traslada el mundo de las ideas platónico (dominio fuente) a la mente del Dios judeo-cristiano (dominio meta) (Hirschberger, 1997). Así el logos matemático es el pensamiento de Dios, que en tanto creador (según los libros bíblicos) deja en su obra de la creación reflejos del logos matemático. En esta línea y a fines del medioevo se realiza otro traslado metafórico más físico desde la imagen del constructor de máquinas o ingeniero medieval renacentista (Prigogine \& Stengers, 2004): el Dios creador ha dejado como un constructor o artista su huella matemática en su obra. En los albores de la modernidad otro sacerdote y teólogo cristiano Giordano Bruno, considerado el mayor filósofo del Renacimiento (Bruno, 2018), entiende que no puede haber dualismo entre el misterioso y mítico mundo supralunar y el sublunar, es más, no puede haber dualismo entre Dios y el mundo (panteísmo). Por eso, desde la metáfora de la emanación de Plotino (presente en Enéadas) piensa que el mundo emana de Dios (dominio meta) como el agua de una fuente (dominio fuente) y por ello Dios -y su logos matemático - está presente en todas las cosas como el alma del mundo (Bruno, 2018) (Newton utilizará luego esta metáfora de la emanación, ver infra punto 7.2).

Para diferenciar con la postura de Galilei, es fundamental destacar que el logos inmanente para G. Bruno no se identifica con la matemática puraxiii, por lo que no puede haber una explicación matemática exhaustiva de la realidad natural, "porque una cosa es jugar con la geometría y otra verificar con la naturaleza" (Bruno, 2015, p. 155). Unos años más tarde, Spinoza coincide con Bruno en que Dios es inherente e inmanente a todas las cosas, y lo identifica con la ley matemática que las define y establece (Armstrong, 1995). Por su parte, en R. Descartes (2011) y F. Bacon (1949) encontramos la metáfora del Dios creador visto como un constructor de máquinas que ha dejado las huellas de su ingenio en su obra. Galileo y Newton (Newton, 1982) convencidos en el mismo sentido- buscan los caracteres claros y distintos de la matemática en la realidad que el Dios matemático ha producido e intentan contribuir así a la depuración del cristianismo suprimiendo los misterios que en él aún perviven (Cassirer, 1993; Armstrong, 1995). Newton reduce a Dios a su sistema mecánico (Newton, 2006) y elimina el misterioso y divino mundo supralunar; la revolución copernicana y la doctrina cristiana de la encarnación del logos contribuyen a uniformizar los dos mundos en uno (Kojéve, 1964). Galileo como G. Bruno rompe el dualismo supralunar-sublunar pero opta por una uniformización que haga posible el tratamiento exhaustivo por la matemática, "una matemática que ya no es pitagórica, es decir, simbólica y analógica en sentido moral, religioso y místico, como todavía lo es la mathesis bruniana del De monade, numero et figura, sino sencillamente matemática" (Bruno, 2015, p. VII). Así la realidad termina siendo —en su esencia-matemática, es como un libro escrito en caracteres matemáticos "puros" (Galilei, 1981).

7.2) Metáfora de Newton: de Dios infinito y eterno (dominio meta) emanan como de una fuente (dominio fuente) - el espacio, la materia y el tiempo: como Descartes y Galileo, Newton entiende que la naturaleza está matematizada porque ha salido de la mente de Dios que la ha producido (Newton, 1982). Pero la idea de creación no es tomada desde la operación de un ser trascendente que crea y permanece distinto de su creación, sino que (en sintonía implícita con G. Bruno y B. Spinoza) la entiende desde la metáfora de la emanación plotiniana. Newton intentó explicar el universo físico, "considerando a Dios como una parte esencial de este sistema. En la física de Newton la naturaleza era completamente pasiva: Dios era la única fuente de actividad" (Armstrong, 1995, p. 351). Así, Dios le era necesario para dar el impulso inicial y poner todo el cosmos en movimiento. Pero dentro de un espacio infinito se preguntaba: “¿Dónde encajaba Dios dentro de él? ¿No era el mismo espacio en cierto modo divino y no poseía, como Dios, los atributos de eternidad e 
RIIE (2021), Año 12 (15), 68-92.

DOI: http://dx.doi.org/10.30972/riie.12155570
La metáfora como mecanismo de inteligencia, creación y comunicación en ciencias duras $e$ ingeniería y su recupero en la docencia universitaria.

infinitud?" (1995, p. 353). Aquí hay un vacío hermenéutico que es llenado por la vía metafórica. La solución la dio nuevamente la metáfora de la emanación plotiniana ya que la materia es el efecto emanante de Dios: De extensione [...] tanquan Dei effectus emanativus" (Newton, 2006, p. 5), el espacio también es un efecto que emana del ente primero: "Spatium sit entis primario existentis effectus emanativus" (2006, p.7), y se afirman similitudes sobre la duración: "Deque Duratione similia possunt affirmari (2006, p.7). Así, de Dios emanan la materia, el espacio, el tiempo y las leyes que informan la naturaleza, lo cual ubica el sabio inglés en una postura panteísta (Armstrong, 1995).

7.3) Metáfora de Newton de la honda (dominio fuente) para visualizar la fuerza gravitatoria Tierra-Luna (dominio meta): la realidad escrita o construida en caracteres matemáticos, tiene un ladrillo básico que proviene de un traslado metafórico. En su obra magna Philosofiae Naturalis Principia Matematica (en adelante Principia) Newton tomando una analogía de Huygens compara la fuerza de gravedad como la tensión que aparece en una cuerda al hacer girar una piedra en una honda.

Aquí hay un vacío hermenéutico que es llenado metafóricamente. La Definición $\mathrm{V}$ del pórtico a Principia trae concretamente este traslado metafórico que será la clave de toda la construcción teórica de los libros I y II de Principia; para luego aplicar toda la teoría al sistema del mundo en el libro III:

Definición V: Fuerza centrípeta es aquella por la cual los cuerpos son arrastrados o impelidos, o tienden de cualquier modo hacia un punto como hacia un centro. De este tipo es la gravedad [...] Una piedra que da vueltas en una honda se esfuerza por alejarse de la mano que la hace girar y por ese esfuerzo distiende la honda tanto más cuanto que con mayor velocidad gira, y sale volando tan pronto como es liberada. Llamo fuerza centrípeta a aquella que se opone a ese esfuerzo [...] Y lo mismo debe entenderse de todos los cuerpos que giran en órbitas. (Newton, 1982, p. 29) (el subrayado es propio)

Newton confía en que toda la realidad pueda ser explicada matemáticamente en base a interacciones entre partículas conforme a este modelo (Newton, 1982). Esta intuición de Newton dará una época gloriosa de éxitos a la nueva ciencia, ya que sustentó producciones que se extendieron más allá del caso concreto de la mecánica y que fueron etiquetadas por Einstein \& Infeld como la "Génesis y ascensión del punto de vista mecánico" (1974, p. 11).

7.4) Metáfora de Hooke-Newton sobre la dilución de la gravitación (dominio meta) a partir de la dilución del sonido y de la luz (dominio fuente): aquí nos es necesario combinar la investigación histórica con los indicios presentes en Principia. J. Kepler había realizado un traslado metafórico importante: así como la superficie de una esfera aumenta con el cuadrado de la distancia a su centro (dominio fuente: la geometría), la intensidad de un sonido o de la luz a partir de una fuente puntual (dominio meta: intensidad sonora o lumínica) se diluye con el cuadrado de la distancia a la fuente (ya que se distribuye sobre una superficie que aumenta con esa ley) (Vallejo, 2005). Esto que hoy puede resultar una perogrullada, es un traslado de gran osadía que se produce desde el espíritu de la época condensado en la metáfora de Galileo. Con base en esta metáfora de Kepler y a través de Robert Hooke llega a Newton este traslado metafórico: como sucede con la dilución de luz y el sonido (dominio fuente), la gravedad también podría diluirse de la misma manera que estos al alejarse de la fuente (dominio meta) (Moledo, 2013). Aquí hay un vacío hermenéutico que es llenado mediante la vía metafórica. La dilución de la gravedad con la inversa del cuadrado resultaba muy sugerente para Newton pues podía vincularla con la 
RIIE (2021), Año 12 (15), 68-92.

DOI: http://dx.doi.org/10.30972/riie.12155570
La metáfora como mecanismo de inteligencia, creación y comunicación en ciencias duras $e$ ingeniería y su recupero en la docencia universitaria.

trayectoria de sección cónica de los cuerpos celestes (circunferencias, elipses, parábolas, hipérbolas), ya que tales trayectorias resultan de un movimiento con fuerza central dependiente de la inversa del cuadrado de la distancia (Newton había trabajado geométricamente estas relaciones en los libros I y II de Principia con intención de aplicarla al sistema del mundo en el Libro III). Newton declara en el Prólogo a su tercera edición que las órbitas de los cometas son "casi" parabólicas, es decir, busca en sus trayectorias esa figura de sección cónica: "resulta manifiesto cómo responden a órbitas casi parabólicas los movimientos de los cometas" (1982, p. 26).

En el Corolario VI de la Proposición IV del primer libro de los Principia enuncia por primera vez la idea de la dependencia de la fuerza gravitatoria con la inversa del cuadrado de la distancia al hablar de cuerpos que se mueven describiendo "círculos" de determinado radio. Newton necesitaba extraer la relación matemática mencionada de la metáfora de la honda (pues la metáfora de la dilución de Hooke — si bien daba en la tecla - sólo sería cabalmente comprendida desde la metáfora del campo, desarrollada por Faraday, Thomson y Maxwell). Llega a esta relación a partir de la analogía con la fuerza centrípeta de un cuerpo en revolución calculada por Huygens, y una combinación con la $3^{\underline{a}}$ Ley de Kepler del movimiento planetario (observamos que la matematización del dominio fuente se traslada al dominio meta). Weinberg (2016) y Boido (1998) refieren la dificultad que Newton tuvo para justificar empíricamente la matematización de su genial metáfora de la honda, dificultad conocida como el fracaso de la prueba lunar. Parecen aquí resonar las advertencias de Giordano Bruno: "Una cosa es jugar con la geometría y otra verificar con la naturaleza" (2015, p.155). Newton esperó hasta obtener nuevos datos astronómicos empíricos que se ajustaran aproximadamente a su idea. Trece años después del primer intento fallido, una medición de Picard de mayor exactitud hizo que las diferencias se achicaran. Ante el fracaso empírico de la prueba lunar estos esquemas obtenidos desde el traslado metafórico no son desechados por Newton y vuelven a resurgir años después ante nuevos datos astronómicos. Son un núcleo fuerte de su construcción teórica, la ubicación de la imagen de la honda en la definición V de Principia así lo manifiesta. El mismo Newton en el prefacio a la primera edición de Principia, explica que la tardanza en publicar se debió al problema de la prueba lunar, a que sus cálculos conforme a su teoría no se ajustaban a la realidad: "Pero después de haber empezado a considerar las desigualdades de los movimientos lunares [...] postpuse la publicación hasta haber investigado esas materias" (Newton, 1982, p. 7). Es interesante para la docencia esta "separación" entre física y matemática, para no reducir — sin más - la primera a la segunda o —como lo señala Korzybski (1951) — confundir el mapa con el territorio.

7.5) Metáfora de Thomson sobre la disminución de temperatura (dominio meta) a partir de la dilución de la gravitación (dominio fuente): William Thomson (Lord Kelvin) influenciado por la dilución de la fuerza de gravedad con la inversa del cuadrado de la distancia, establece una analogía entre el calor y la atracción a distancia. Aquí hay un vacío hermenéutico que es llenado metafóricamente. Así como la luz, el sonido o la gravedad disminuyen con el cuadrado de la distancia, así también la temperatura en torno a una fuente puntual de calor. Esta metáfora de Thomson es referenciada y tomada luego por Maxwell en sus papers (Maxwell, 1855). Observamos aquí que lo que fue dominio meta en un ámbito se transforma en dominio fuente de otro. Esto indica la fecundidad de los traslados y la eficacia de los llenados del vacío hermenéutico por el mecanismo. Metodológicamente se confirma la presencia de los indicadores definidos en supra punto 3 en base a los procedimientos empíricos allí declarados. 
RIIE (2021), Año 12 (15), 68-92.

DOI: http://dx.doi.org/10.30972/riie.12155570
La metáfora como mecanismo de inteligencia, creación y comunicación en ciencias duras $e$ ingeniería y su recupero en la docencia universitaria.

7.6) Metáfora de Priestley sobre la disminución de la fuerza eléctrica con la inversa del cuadrado de la distancia: la ley de gravitación es trasladada metafóricamente al ámbito de la electrostática, bajo una intuición metafórica de J. Priestley ante una carta de B. Franklin donde se mencionaba un fenómeno del que se deducían acciones eléctricas nulas en el interior hueco de un conductor cargado. Priestley advirtió la analogía con la acción de fuerzas gravitatorias nulas en el interior de un cuerpo hueco con una cáscara masiva, lo cual sólo sucede si vale para las fuerzas la ley de la inversa con el cuadrado de la distancia (Priestley, 1767). Esta metáfora es referida por Halliday \& Resnick (1977). Observamos como la matematización desde un dominio fuente se traslada hacia el dominio meta.

7.7) Metáfora de Michel Faraday sobre las líneas de fuerza magnética (dominio meta) vistas como bandas elásticas (dominio fuente): Faraday (1855) había visualizado mediante una aguja suspendida de un hilo y mediante limaduras de hierro unas como líneas magnéticas asociadas a las proximidades de los polos de un imán. La atracción y la repulsión entre polos magnéticos hacía "sentir" a estas líneas con propiedades de elasticidad (líneas que después dieron entidad a la noción de campo, eliminando la mítica acción a distancia de Aristóteles-Newton). Aquí hay un vacío hermenéutico que es llenado por la vía metafórica. Esta imagen mental de las líneas visualizadas como bandas elásticas (Faraday, 1855, p. 416) abría a una concepción muy importante, pueden tratarse de un estado o tensión del éter: "It may be a vibration of the hypothetical ether, or a state or tension of that aether" (1855, p. 417). Esto entraba en sintonía con un experimento de 1845 en el que Faraday había detectado interacciones entre la luz y el magnetismo: "Light has been magnetically affected" $(1855$, p. 1), y se preguntaba si la luz misma no era más que una vibración de las líneas de fuerza magnética. Aquí se nota la fecundidad del primer traslado metafórico.

Esto sugería entender los fenómenos eléctricos y magnéticos como propiedades intrínsecas del mismo espacio, desvaneciéndose la necesidad del hipotético éter. Vemos como la metáfora lleva a concepciones de gran trascendencia para el progreso de la ciencia.

7.8) Metáfora hídrica de Maxwell sobre las líneas de fuerza de Faraday (dominio meta): las imaginó como líneas de corriente de un líquido en movimiento entre una fuente y un sumidero (dominio fuente): aquí hay otro vacío hermenéutico que es llenado metafóricamente. Con este traslado Maxwell matematiza desde el dominio fuente hidráulico — palpable y conocido_ el dominio meta (Maxwell, 1855). La presión resulta disminuir con la inversa del cuadrado de la distancia (dominio fuente), lo que se corresponde con la variación de la fuerza entre cargas eléctricas (dominio meta). Maxwell vincula analógicamente los dos dominios mediante una metáfora estructural (Lakoff \& Jonhson, 2007), asociando la fuente de líquido con la carga eléctrica, la presión del fluido con el potencial eléctrico, las líneas de corriente de fluido con las líneas de fuerza del campo eléctrico, con lo cual la velocidad del fluido termina siendo relacionada con la intensidad del campo eléctrico. La metáfora hídrica no sólo vehiculiza el mapeo matemático, sino que también permite dar sentido a conceptos matemáticos que expresan la teoría electromagnética: el flujo y la circulación de un campo vectorial como descripción y concepto inspirados en el flujo y la circulación de un fluido. También da sentido a operadores matemáticos abstractos que son utilizados por Maxwell para expresar sus cuatro famosas ecuaciones en forma diferencial: la divergencia de un campo vectorial — divergir de fluido desde una fuente puntual- y el rotor de un campo vectorial - como la tendencia a rotar de fluido en las cercanías de un punto-. Estos conceptos suelen presentarse en la enseñanza superior en un estado de catacresis, es decir en el estado de un olvido de su origen metafórico. 
RIIE (2021), Año 12 (15), 68-92.

DOI: http://dx.doi.org/10.30972/riie.12155570
La metáfora como mecanismo de inteligencia, creación y comunicación en ciencias duras $e$ ingeniería y su recupero en la docencia universitaria.

Recuperar la imagen que los conecta con lo familiar es algo muy interesante para su conceptualización.

7.9) Inteligencia de Maxwell sobre los campos eléctricos (dominio meta) a partir de la metáfora de Thomson sobre la temperatura (dominio fuente): Maxwell fue discípulo de Lord Kelvin en el tema de la analogía. Razona que, si la fuente de calor de Thomson fuera una fuente de un líquido, las superficies de igual temperatura podrían equipararse a superficies de igual presión del líquido. Maxwell entiende que a partir de una analogía matemática entre fenómenos de dos ámbitos distintos es posible pensar uno de ellos desde el otro (Maxwell, 1855), produciéndose una simbiosis fructífera para avanzar en la comprensión de la naturaleza (observamos nuevamente como una matematización en el dominio fuente se traslada al dominio meta). Avanzando en la idea de campo (que compartía en forma pionera con Faraday y Thomson) y dejando atrás la aristotélica y teológica acción a distancia (que todavía pervivía en la obra de Newton), Maxwell imagina "tubos de fuerza" por los que circula el fluido, siendo la velocidad del fluido en el tubo proporcional a la llamada intensidad del campo:

If we consider these curves not as mere lines, but as fine tubes of variable section carrying an incompressible fluid then, since the velocity of the fluid is inversely as the section of the tube (...) in this way we might represent the intensity of the force (1855, p. 158).

7.10) Metáfora sustancializadora de Fourier sobre la conducción del fluido (dominio fuente) calórico (dominio meta): los fenómenos de conducción del calor fueron analizados por Joseph Fourier (1822) imaginando modelos que intentan describir lo que pasa entre un punto y otro muy cercano de un conductor que "transporta" calor como si de un fluido se tratara. Este análisis pionero de Fourier inspira la modelización matemática de toda una serie de fenómenos catalogados "de transporte" y constituyen metáforas sustancializadoras según Lakoff \& Johnson (2007).

La imagen de Fourier es utilizada y referida por Thomson (1872) en el avance de sus estudios de electrostática y magnetismo. Si bien superada por consideraciones energéticas, la metáfora de un líquido que fluye permite captar visualmente la diferencia entre calor (cantidad de líquido aportado o quitado) y temperatura (nivel de líquido) (Einstein \& Infeld, 1974), captar el equilibrio térmico mediante vasos comunicantes (Hewitt, 2007) y también visualizar el concepto de capacidad calorífica (Einstein et al.,1974).

7.11) Metáfora de Ohm que permitió el estudio de la conducción eléctrica (dominio meta) a partir de la conducción térmica estudiada por Fourier (dominio fuente): ante el vacío de explicación satisfactoria de los fenómenos eléctricos, Ohm realizó un traslado metafórico: pensó que la electricidad podría comportarse del mismo modo que el calor, jugando la diferencia de potencial un papel análogo a la diferencia de temperatura de Fourier. Esto le permitió encontrar un modelo matemático formalmente idéntico para la conducción galvánica: "Die Form und Behandlung der so erhaltenen Differenzialgleichungen ist denen für die Warmebewegung durch Fourier und Poisson" xiv (Ohm, 1827, p. 5). Notemos cómo opera una analogía entre los flujos calóricos (7.10), hídricos (7.8) y eléctricos, que se traduce en un esquema matemático común.

Baste lo dicho como muestra de los procesos metafóricos operantes en el período fundacional de la ciencia moderna. En todo este recorrido ha quedado de manifiesto algo frecuente y que es consecuencia de la presencia en el mecanismo 
RIIE (2021), Año 12 (15), 68-92.

DOI: http://dx.doi.org/10.30972/riie.12155570
La metáfora como mecanismo de inteligencia, creación y comunicación en ciencias duras $e$ ingeniería y su recupero en la docencia universitaria.

metafórico de los indicadores propuestos sobre lo cognoscitivo, lo creativo y lo comunicativo: lo conquistado cognoscitivamente en un campo del saber como perteneciente al dominio meta, se convertía fructíferamente en conocimiento perteneciente al dominio fuente en otra disciplina, dándose un progreso en la evolución del conocimiento.

\section{Conclusiones}

A continuación, pasamos revista al cumplimiento de cada uno de los objetivos de la investigación y validación de la hipótesis sustantiva de investigación.

8.1) Cumplimiento del objetivo 1: como objetivo 1 de la investigación nos propusimos manifestar la pertinencia - como eficacia y epistémicamente- de la metáfora en el cubrimiento del vacío hermenéutico. Es evidente que la cadena de cubrimientos metafóricos que se inicia con la metáfora de la honda de Newton y su revestimiento matemático también metafórico (ver 7.3) es índice de una descripción fundante que ha sido sólida en el cubrimiento del vacío en el dominio meta (indicadores 1, 2 y 3 ) ya que el mismo se ha transformado en fecundo dominio fuente de nuevas producciones. En este proceso descripto en el punto 7 se observa claramente el logro del objetivo 1. La pertinencia de la metáfora en el cubrimiento del vacío interpretativo ha quedado evidenciada por la desaparición estable de tal vacío y por el paso a estado de catacresis de la imagen metafórica (olvido actual de su origen metafórico). El cumplimiento de este primer objetivo abonó la hipótesis sustantiva de investigación -que se completó con el revestimiento matemático también de base metafórica (traslado de matematizaciones desde el dominio fuente)-: Los modelos que hacen avanzar la ciencia dura surgen mediante (o se basan en) procesos metafóricos sustentados en conocimientos que provienen de la vida cotidiana, en tanto son - dichos modelos - continuidad de estos mismos mecanismos (metafóricos). Es notable que las síntesis de la ciencia moderna en la Mecánica clásica y en el electromagnetismo, se remonten a unos orígenes en los que encontramos imágenes cotidianas: una honda (7.3), bandas elásticas (7.7) y flujos de agua (7.8).

8.2) Cumplimiento del objetivo 2: en el objetivo 2 nos propusimos manifestar la lógica del "contexto de descubrimiento", esto fue mostrado en el punto 7 a través de la puesta en escena de la metáfora que operó lógicamente en cada instancia manifestada allí. Esta operación es lógica en cuanto que se basa no en la irracionalidad ni en la casualidad sino en una cantera de analogías construida diacrónicamente y que son esquemas que han venido teniendo éxito (Vico, 1995) y en los que hace pie la lógica del traslado metafórico. La metáfora proporciona la regla para que funcione el razonamiento abductivo y se genere la hipótesis en el llamado contexto de descubrimiento, como lo expresamos en 6.3 y 6.7. Esta circunstancia abona la pertinencia de la hipótesis sustantiva sobre la base metafórica de los modelos científicos.

8.3) Cumplimiento del objetivo 3: en el objetivo 3 nos propusimos mostrar que hay una "validez empírica" de la metáfora, en tanto la imagen trasladada tiene que ver con lo real y no es una pura fantasía que llegó casualmente a tener éxito. El recorrido presentado en el punto 7 muestra que la visión de "dos en uno", a través de la focalización de elementos fácticos relevantes en base a la praxis como cantera de analogías, logra el éxito operacional del cubrimiento del vacío hermenéutico dentro del margen de los errores experimentales y generando una teoría o explicación apropiada.

Samaja lo dice de este modo: 
RIIE (2021), Año 12 (15), 68-92.

DOI: http://dx.doi.org/10.30972/riie.12155570
La metáfora como mecanismo de inteligencia, creación y comunicación en ciencias duras $e$ ingeniería y su recupero en la docencia universitaria.

en toda teoría están las huellas de experiencias ya conquistadas y de las cuales se han extraído por reflexionamiento los elementos invariantes que permiten anticiparla como si dijéramos a priori. En toda construcción lógica hay una fuerza demostrativa porque toda lógica es un ri-corsi de un corsi protagonizado con anterioridad y en

el cual la propia subjetividad se ha constituido. (2004, p. 134)

Como la cantera de analogías está consolidada o validada por sus éxitos pragmáticos, esto es por su validación empírica, es entendible que tanto el traslado metafórico como su revestimiento matemático tengan fundamento en la cosa extra mental y no sean una fantasía útil, pero en el fondo falsa.

La hipótesis sustantiva es abonada por el cumplimiento del objetivo 3, ya que, si hay validez empírica de la metáfora, es decir, si esa imagen tiene que ver con lo real y no es una pura fantasía que llegó casualmente a tener éxito, esto boga por la validez de la hipótesis sustantiva: Los modelos que hacen avanzar la ciencia dura se basan en procesos metafóricos...

8.4) Cumplimiento del objetivo 4: en el objetivo 4 nos propusimos mostrar que el "revestimiento teórico" o matemático de la metáfora es posible. Para esto, en el punto 7.3. mostramos como el revestimiento matemático de la metáfora de la honda se llevaba a cabo por consideraciones geométricas en base a la metáfora de la dilución del sonido de Kepler y Hooke (punto 7.4) y a estudios de Huygens sobre la rotación.

Esta matematización del dominio meta gravitatorio, se convirtió en dominio fuente de la matematización en el dominio de la electrostática (punto 7.6), en el de la dilución de temperatura (punto 7.5), en el de la conducción del calor (puntos 7.10 y 7.11), en el de la electrodinámica (punto 7.11), pasando luego a la concepción del campo en el dominio del electromagnetismo (puntos 7.7, 7.8 y 7.9). El hecho señalado del olvido del origen metafórico de los conceptos y funcionamientos se produce por ese paso al "modelo" que es su revestimiento lógico-matemático. Si el revestimiento lógico matemático de la metáfora es posible, esto boga claramente por la pertinencia de la hipótesis sustantiva: Los modelos que hacen avanzar la ciencia dura surgen mediante (o se basan en) procesos metafóricos sustentados en conocimientos que provienen de la vida cotidiana, en tanto dichos modelos son continuidad de estos mismos mecanismos (metafóricos).

\section{Propuesta educativa}

Los resultados obtenidos abren oportunidades a la docencia en educación superior que resumimos a continuación:

9.1) Recupero de la metáfora que usó el científico como "trasposición didáctica": si en la producción del conocimiento científico obra sine qua non la metáfora, su recupero sería una oportuna trasposición didáctica (Chevallard, 1985).

Por su naturaleza, este recupero conecta con saberes familiares, implicando al alumno en una construcción significativa del conocimiento.

9.2) Poner al alumno en la estela del investigador: validada epistemológicamente la lógica del mecanismo metafórico en el "contexto de descubrimiento" (que fuera excluido desde Reichenbach como no científico o irracional), es dable incorporarlo dentro de la actividad propiamente científica. Para el ámbito de la enseñanza-aprendizaje es relevante tal incorporación, porque habilita el 
RIIE (2021), Año 12 (15), 68-92.

DOI: http://dx.doi.org/10.30972/riie.12155570
La metáfora como mecanismo de inteligencia, creación y comunicación en ciencias duras $e$ ingeniería y su recupero en la docencia universitaria.

recupero de la situación problemática o vacío que desencadenó el cubrimiento metafórico. Si el docente adopta tal enfoque problematizador habilitando la actividad creativa-imaginativa (metafórica) del alumno, se estará invitando a este a recorrer el camino del investigador y del científico desmitificando la ciencia como asunto de gente excepcional para incorporarlo al torrente creativo.

9.3) Un "resquicio" para la creatividad o el ejercicio del ingenio: Piaget ha dicho que en la ciencia física hay un interés por la axiomatización, todo se desarrolla "como si el físico se esforzara, con sentimiento de culpabilidad, en esconder lo que se debe a la experimentación y en hacer creer con una cierta hipocresía que todo lo ha deducido [1979, 125-126]" (Samaja, 2004, p. 30). Esta actitud suele trasladarse a la enseñanza cuando se resuelve en una transmisión de contenidos, prolijamente secuenciados y encastrados, donde no existe "resquicio" para la creatividad o el ejercicio del ingenio. Desde el enfoque problematizador de la educación y desde la recuperación de los escenarios en los que operaron las metáforas originantes del conocimiento científico, la imaginación impregnada de praxis podrá tener un lugar en la educación.

\section{Colofón}

Esta investigación pretendió ser un aporte a la docencia. Entendemos, por los resultados obtenidos, que se abre para ella la posibilidad bien fundamentada de abrir un intersticio en la controlada transmisión de productos ajenos bien trabados, secuenciados (y con apariencia de verdad intocable), para darle un lugar — desde la verosimilitud-, a la verdad humana y significativa, desde esa construcción metafórica en la que puede ingresar el alumno y sus circunstancias y donde —quizás- pueda brillar la creatividad propia y digna de su humanidad.

\section{Referencias bibliográficas}

Abbagnano, N. y Visalberghi, A. (1992). Historia de la pedagogía. Madrid, España: Fondo Cultura Económica.

Aristóteles (2004). Poética. Bs.As., Argentina: Quadrata.

Armstrong, K. (1995). Una historia de Dios. Barcelona, España: Paidós.

ASA (American Scientific Affiliation). (1949). Journal of the American Scientific Affiliation Bulletin. Vol 1, Number 1. Wheaton: ASA.

Bacon, F. (1949). Novum Organum. Bs. As., Argentina: Losada.

Black, M. (1966). Modelos y metáforas. Madrid, España: Tecnos.

Boido, G. (1998). Noticias del planeta Tierra. Bs. As., Argentina: A-Z editora.

Boltzmann, L. (1986). Escritos de mecánica y termodinámica. Madrid, España: Alianza.

Bruner, J. (2004). Realidad mental y mundos posibles. Barcelona, España: Gedisa.

Bruno, G. (2015). La cena de las cenizas. Madrid, España: Tecnos. 
RIIE (2021), Año 12 (15), 68-92.

DOI: http://dx.doi.org/10.30972/riie.12155570
La metáfora como mecanismo de inteligencia, creación y comunicación en ciencias duras $e$ ingeniería y su recupero en la docencia universitaria.

Bruno, G. (2018). De la causa, principio y uno. Madrid, España: Losada.

Cassirer, E. (1968). Antropología Filosófica. México: Fondo Cultura Económica.

Cassirer, E. (1993). Filosofía de la Ilustración. Madrid, España: Fondo Cultura Económica.

Conant, J. (1963). Entendimiento de la Ciencia. Bs. As, Argentina: Plaza \& Janés.

Chevallard, Y. (1985). La transposición didáctica. Bs. As., Argentina: Aique.

Descartes, R. (2011). Discurso del Método. Madrid, España: Gredos.

Einstein, A. (1983). Notas autobiográficas, Madrid: Alianza.

Einstein, A. \& Infeld, L. (1974). La Física aventura del pensamiento. Bs. As., Argentina: Losada.

Faraday, M. (1855). Experimental researches in Electricity. Vol. III. London, U.K.: Bernard Quaritch.

Faraday, M. (1859). Experimental researches in Chemistry and Physics. London, U.K.: Richard Taylor and William Francis.

Fourier, J. (1822). Théorie analytique de la chaleur. Paris, France: Didot.

Galilei, G. (1981). El Ensayador. Bs. As., Argentina: Aguilar.

Gentner, D. \& Gentner, D. R. (1982). Flowing waters or teeming crowds: Mental models of electricity. Massachusetts, USA: Bolt Beranek and Newman Inc.

Halliday, D. \& Resnick, R. (1977). Física. Parte 2. México: C.E.C.S.A.

Hegel, G. W. F. (1982). Ciencia de la lógica. Bs. As., Argentina: Solar.

Herrero, M. A. (2012). Instrumentalismo y realismo en la física de James C. Maxwell. Naturaleza y Libertad. Revista de Estudios Interdisciplinares, (1), 77-138. https://doi.org/10.24310/nyl.v1i1.3976

Hesse, M. (1970). The function of models: a dialogue. En Models and analogies in science (pp. 7-56). Indiana: Univ. of Notre Dame.

Hewitt, P. (2007). Física Conceptual. México: Pearson Addison Wesley.

Hirschberger, J. (1997). Historia de la Filosofía. Antigüedad, Edad Media, Renacimiento. Tomo I. Barcelona, España: Herder.

Kojéve, A. (1964). L’origine chrétienne de la science moderne. En M. Koyré (1964). L'Aventure del' esprit (pp. 295-306). París, France: Hermann Rodríguez.

Korzybski, A. (1951). El papel del lenguaje en los procesos perceptivos. En Perception: An approach to personality. Nueva York: R. R. Blake y G. V. Ramsey. Recuperado de http://esgs.free.fr/es/art/ak3.htm 
RIIE (2021), Año 12 (15), 68-92.

DOI: http://dx.doi.org/10.30972/riie.12155570
La metáfora como mecanismo de inteligencia, creación y comunicación en ciencias duras $e$ ingeniería y su recupero en la docencia universitaria.

Laborda Gil, X. (1981). Racionalismo y empirismo en la lingüística del siglo XVII. [Tesis Doctoral]. Universidad de Barcelona. Barcelona, España. Recuperado de https://www.tdx.cat/bitstream/handle/10803/1727/TESIS LABORDA.pdf?sequ ence $=1$ \&isAllowed $=y$

Ladrière, J. (1978). El reto de la racionalidad. Salamanca, España: Sígueme.

Lakoff, G. \& Johnson, M. (2007). Metáforas de la vida cotidiana. Madrid, España: Cátedra.

Lupasco, S. (1963). Las tres materias. Bs. As., Argentina: Sudamericana.

Maxwell, J. C. (1855). On Faraday's Lines of Force. In W. D. Niven (Ed.). (1965a). The scientific papers of James Clerck Maxwell (pp.155-229). Volume 1. Nueva York, USA: Dover Publications.

Moledo, L. (2013). Historia de las ideas científicas. Bs. As., Argentina: La Página.

Nagel, E. (2006). El Estatus cognoscitivo de las teorías. En La estructura de la ciencia (pp.151-209). Barcelona, España: Paidós - Surcos.

Newton, I. (1846). The mathematical principles of natural philosophy. [traducción A. Motte]. New York, U.S.A.: Daniel Adee. [foto-duplicado].

Newton, I. (1871). Philosofiae Naturalis Principia Matematica, Glasgow, U.K.: J. Maclehose. [corresp. a 3ª edición en latín -1726- en foto-duplicado].

Newton, I. (1982). Principios matemáticos de la Filosofía Natural. [Estudio, traducción y notas de Antonio Escohotado]. Madrid, España: Tecnos.

Newton, I. (2006). De Gravitatione et æquipondio fluidorum. Recuperado de www.newtonproject.ox.ac.uk/view/texts/normalized/THEM00093

Newton, I. (2011). Principios matemáticos de la filosofía natural. [traducción E. Rada]. Madrid, España: Alianza.

Nicolás de Cusa. (1973). La Docta Ignorancia. Madrid, España: Aguilar.

Ohm, G. S. (1827). Die galvanische Kette, mathematisch bearbeitet. Berlín, Deutschland: T. H. Rieman.

Oliveras, E. (2007). La metáfora en el arte. Bs. As., Argentina: Emecé.

Ortega y Gasset, J. (1985). Las dos grandes metáforas. En El espectador. Madrid, España: Biblioteca Nueva.

Palma, H. (2004). Metáforas en la evolución de las ciencias. Bs. As., Argentina: J. Baudino.

Peirce, Ch. (1974). La ciencia de la semiótica. Bs. As., Argentina: Nueva Visión.

Peirce, Ch. (2001). Razonamiento. En Grupo de Estudios Peirceanos (Comp.). Recuperado de https://www.unav.es/gep/Reasoning.html 
RIIE (2021), Año 12 (15), 68-92.

DOI: http://dx.doi.org/10.30972/riie.12155570
La metáfora como mecanismo de inteligencia, creación y comunicación en ciencias duras $e$ ingeniería y su recupero en la docencia universitaria.

Peirce, Ch. (2003). Cómo teorizar. En Grupo de Estudios Peirceanos (Comp.). Recuperado de https://www.unav.es/gep/ComoTeorizar.html

Penrose, R. (1996). La nueva mente del emperador. México: Fondo Cultura Económica.

Piaget, J. (1991). Seis estudios de psicología. Barcelona, España: Labor.

Priestley, J. (1767). The History and Present State of Electricity, with original experiments. London, U.K.: J. Dodsley, J. Johnson and T. Cadell.

Prigogine, I. \& Stengers, I. (2004). La Nueva Alianza. Metamorfosis de la Ciencia. Madrid, España: Alianza.

Rey Pastor, J. y Babini, J. (1985). Historia de la Matemática. Vol. 1. Barcelona, España: Gedisa.

Ricœur, P. (1977). La Metáfora Viva. Bs. As., Argentina: Megápolis.

Rodríguez Rodríguez, R. (2005). Abducción en el contexto del descubrimiento científico. Revista Filosofía, XLIII (109/110), 87-97. https://revistas.ucr.ac.cr/index.php/filosofia/article/view/7502/7173

Samaja, J. (1996). El lado oscuro de la razón. Buenos Aires: JVE Episteme.

Samaja, J. (2004). Epistemología y Metodología. Bs. As., Argentina: Eudeba.

Thomson, W. (1872). Papers on Electrostatics and Magnetism. London, U.K.: Macmillan and Co.

Vallejo, F. (2005). Manualito de imposturología Física. Bs.As., Argentina: Taurus.

Vico, G. (1995). Ciencia Nueva. Madrid, España: Tecnos.

Weinberg, S. (2016). Explicar el mundo. Barcelona, España: Taurus.

Windelband, W. (1953). Historia de la Filosofía Antigua. Bs. As., Argentina: Nova. 
RIIE (2021), Año 12 (15), 68-92.

DOI: http://dx.doi.org/10.30972/riie.12155570
La metáfora como mecanismo de inteligencia, creación y comunicación en ciencias duras $e$ ingeniería y su recupero en la docencia universitaria.

Apéndice: Sistema de matrices de datos (esquema de construcción del dato)
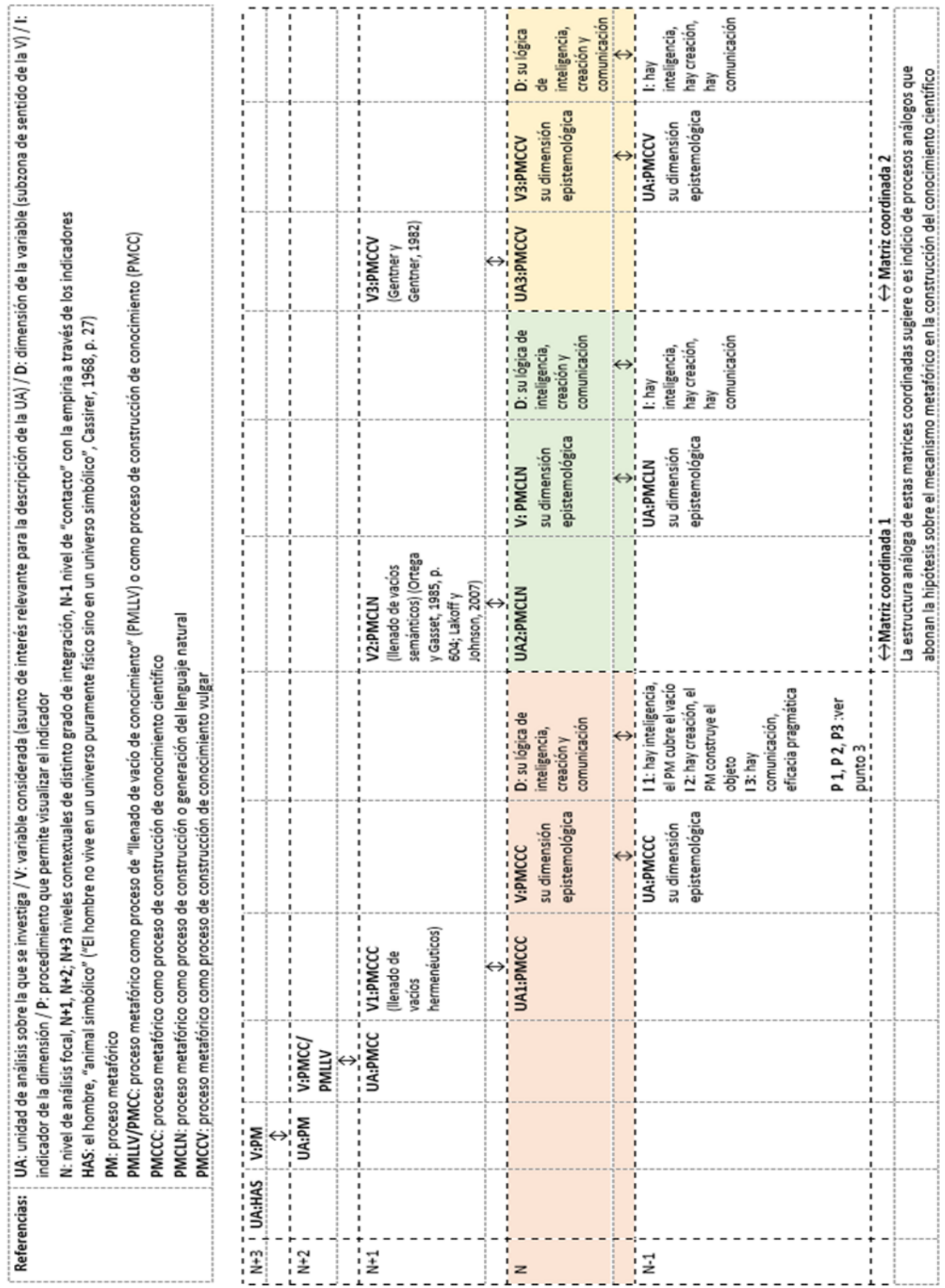
RIIE (2021), Año 12 (15), 68-92.

DOI: http://dx.doi.org/10.30972/riie.12155570
La metáfora como mecanismo de inteligencia, creación y comunicación en ciencias duras $e$ ingeniería y su recupero en la docencia universitaria.

\section{Notas}

i Magnasco, Humberto. (2019). "Bases epistémicas del surgimiento de la metáfora, como mecanismo de inteligencia, creación y comunicación en ciencias duras e ingeniería. Incidencia en la Docencia Universitaria". U.T.N. Directora: Dra. Emilas Lebus; Co-director: Dr. Jorge Noro. ii Nos referimos al ingeniero Mario Báncora, investigador del Berkeley Radiation Laboratory.

iii Cátedra: Física Electrónica, 3er. año de Ingeniería Electricista, U.N.R. (año 1983).

iv Confesamos que nos preguntábamos: ¿Son válidas —epistemológicamente hablando- las "corazonadas"? Papers en inglés se refieren a la corazonada científica mediante la palabra "hunch": "An intuitive feeling about something" (ASA, 1949, p.7)

$\checkmark$ Ya J. Dewey bajo la influencia de Peirce, Darwin y Hegel dice que el sujeto cognoscente no existe como entidad totalmente definida antes de una investigación, sino que se constituye en ella y para ella. Por eso distingue entre interacción que acontece entre entidades definidas y estables, y transacción, proceso constitutivo de los mismos términos interesados, en particular del "cognoscente" y de lo que es "conocido" (Abbagnano y Visalberghi, 1992, pp. 437-443).

vi "Los objetos de esta forma de saber se presentan siempre como siendo seres complejos; es decir, totalidades que contienen partes diferenciables en calidad y en cantidad. Se presentan como objetos fragmentados o fragmentables de diferentes maneras y, por añadidura, cada plano de fragmentación admite ser estudiado "mediante un número de variables no inferior a infinito" como lo dice Ashby. [1965]" (Samaja, 2004, p. 53).

vii "Para obtener ideas físicas sin adoptar una teoría física [esto es, recurre a una metáfora estructural que no confunde los hechos del dominio fuente con los del dominio meta] debemos recurrir a la existencia de analogías físicas familiares" (traducción y corchetes propios)

viii "Creo que, en la práctica de la ciencia física, la imaginación debería ser ejercitada para presentar la materia investigada desde todos los puntos de vista posibles, e incluso imposibles; para buscar analogías de semejanza y (digámoslo así) de oposición, inversas o contrapuestas (...) No podríamos razonar sobre la electricidad sin concebirla como un fluido, o una vibración, o alguna otra forma o estado" (traducción propia)

ix "Por una analogía física quiero decir esa similitud parcial entre las leyes de una ciencia y las de otra que hace a cada una de ellas ilustrar al otro" [notar la visión de dos en uno que supera en síntesis y establece enriquecimientos mutuos entre el dominio fuente y el dominio meta, aquí reside el proceso creador] (traducción y corchetes propios)

× Nota: De Principia se hicieron tres ediciones en latín (1687, 1713 y 1726). Dos años después de la muerte de Newton, Andrew Motte tradujo la obra al inglés (hubo luego otras dos traducciones a este idioma en el siglo XVIII pero la de Motte fue la que se siguió editando). En 1930 Florian Cajori retocó la versión de Motte, y en 1999 I. Bernard Cohen hizo una nueva traducción desde la de Motte en inglés contemporáneo. Antonio Escohotado realizó la primera traducción al español utilizando la tercera edición en latín y la traducción de Motte. Una nueva traducción de Principia al castellano desde el latín es la de Eloy Rada mencionada en el listado. Nosotros hemos utilizado la versión en latín para salir de las ambigüedades que nos presentaron las traducciones al castellano y al inglés.

xi Varios estudiosos -entre los que se cuentan filósofos, lingüistas, matemáticos y científicosinsisten en el valor cognoscitivo de la metáfora, entre ellos: G. Vico, Ch. Peirce, H. Gadamer, P. Ricœur, M. Black, J Ortega y Gasset, T. Kuhn, G. Lakoff, M. Johnson, T. Brown, R. Núñez (Oliveras, 2007, pp. 183-200). "Uno de los rasgos sobresaliente de la moderna metaforología es su insistencia en la relación entre metáfora e investigación científica y, en general, entre metáfora y conocimiento" (Oliveras, 2007, p. 186).

xii "(...) entendiendo aquí por abducción cualquier modo o grado de aceptación de una proposición como verdad, porque se ha descubierto un hecho o hechos cuya ocurrencia resultaría necesaria o probable en caso de que la proposición fuera verdadera" (Peirce, 2003).

xiii La concepción sobre la matemática depende de la postura filosófica, G. Bruno dice del número: "que es tomado por el aritmético pura y simplemente, por el músico armónicamente, simbólicamente por el cabalista, y en otras formas diversas por otros locos y otros sabios" (Bruno, 2018, Epístola Proemial).

xiv "La forma y el tratamiento de las ecuaciones diferenciales así obtenidas son los del movimiento térmico de Fourier y Poisson" (traducción propia). 